\title{
Phlebotomine sand flies (Diptera: Psychodidae) in different localities of Al-Baha province, Saudi Arabia
}

\author{
Said A. Doha \\ Research and Training Center on Vectors of Diseases, Faculty of Science building, Ain \\ Shams University, postal code: 11566, Abbassia, Cairo, Egypt.
}

\begin{abstract}
A spot survey was conducted to study the sand fly fauna in Al-Baha province, Saudi Arabia. Six sand fly species belonging to the genus Phlebotomus and three to the genus Sergentomyia were identified. Phlebotomus bergeroti was the predominant species being recorded in all sites and represented $54.4 \%$ of the identified flies. The remaining flies were $P$. sergenti (14.8\%), P. arabicus (13.2\%), P. alexandri (5.3\%), S. tiberiadis (4.9\%), S. antennata (2.4\%), S. clydei (2.1\%), P. papatasi (1.5\%), and P. orientalis (1.3\%). The overall number of males collected (3458) was more than that of females (2637). Within the study period (April to December, 1995), sand flies were more active during the period from July to September. The collected fly species displayed different peaks between June and November. No Leishmania infection was found in any of the dissected females.
\end{abstract}

\section{INTRODUCTION}

Sand flies (Diptera: Psychodidae: Phlebotominae) are of considerable public health importance throughout Middle East countries including Saudi Arabia (Büttiker, 1979, Al-Zahrani et al., 1988). The importance of phlebotomine sand flies attributed mainly to their role as potent vectors of leishmaniasis, a parasitic disease with a wide range of clinical symptoms: cutaneous, mucocutaneous and visceral leishmaniasis. Leishmaniasis currently threatens 350 million people in 88 countries around the world (Desjeux, 2004). Several intriguing questions have marked the epidemiology of leishmaniasis in Saudi Arabia: the etiological agent, nature of the disease, the vector and animal reservoirs. Regarding the etiological agent, Saudi Arabia harbor both L. major (Peters et al. 1985, AlTawfiq and AbuKhamsin, 2004) and L. tropica (Al-Zahrani et al. 1988). These parasites may differ in their nature, vector, and animal reservoir (Killick-Kendrick et al., 1985, Peter et al., 1987) but both parasites are responsible for cutaneous leishmaniasis pathologies.

The transmission cycle of $L$. major was reportedly occurring as zoonotic. In Saudi Arabia, ZCL is transmitted to humans from infected rodent reservoir hosts (Psammomys obesus and Meriones libycus) by the bite of the sand fly vector Phlebotomus papatasi (Peters et al., 1987). Leishmania tropica is another etiological agent responsible for cutaneous leishmaniasis in Saudi Arabia (Al-Zahrani et al., 1989 and Peters et al., 1985). The transmission cycle of $L$. tropica is usually anthroponotic with zoonotic transmission reportedly occurring in some areas (Garifallou et al., 1984, Mebrahtu et al., 1992, Sang et al., 1992). Rock hyraxes, Procavia capensis may serve as the reservoir species in Israel and Kenya; (Svobodova et al., 2006, Sang et al., 1992) and probably in Saudi Arabia although there is no evidence for natural infection within this animal (Al-Zahrani et al., 1989). Another zoonotic focus of $L$. tropica was described from North-Sinai, Egypt (Shehata et al., 2009) where the gerbil Gerbillus pyramidum was found associated. Phlebotomus sergenti is often the implicated sand fly vector in both transmission cycles throughout the Middle East countries including Saudi Arabia (AlZahrani et al., 1988).

Leishmania tropica is a more dangerous health problem than L. major although similar clinical symptoms.

Email of correspondence to Dr. Said A. Doha, Research and Training Center on Vectors of Diseases, Faculty of Science building, Ain Shams University, El Khalifa El Ma'moun St., Abbassia, Cairo, Egypt. Postal code: 11566, TEL: +2 010524 8528, Email: saiddoha@yahoo.com 
Infection by $L$. tropica can cause leishmaniasis recidivans as reported in twelve military personnel of Desert Storm Campaign during 1990-1991 (Magill et al., 1993 and Alborzi et al., 2006). Some viscerotropic cases identified reported to have a travel history to Saudi Arabia and may contract the infection there (Magill et al., 1993). Most cases reported in Saudi Arabia were attributed to L. tropica (AlZahrani et al., 1989). The presence of both leishmania species coupled with the wide distribution of their vectors increases the disease risk in many parts of the kingdom including Al-Baha.

Disease control strategies may require targeting the sand fly vector and mammalian reservoir host responsible for transmission of Leishmania parasites. In the prospective study, the main objectives were to identify the sand fly fauna, map their seasonal abundance for risk prediction and understanding their role in transmission of Leishmania parasite and hence vector incrimination.

\section{MATERIALS AND METHODS}

\section{Study area:}

Al-Baha province is situated between Makkah Al Mukarramah and the Asir region, in south-western Saudi Arabia. It is surrounded by a number of cities, including Taif on the north, Beesha on the east, Abha on the south and the Red Sea coast city of Al-Qunfuda on the west. AlBaha is divided into six sectors (Fig.1.).

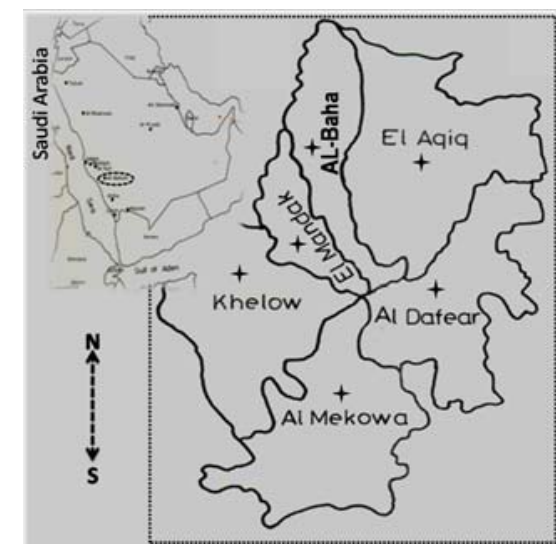

Fig.1. The map of study area showing different sectors inside Al-Baha Province, Saudi Arabia.

Al-Baha province represents different altitudes; areas with altitude more than 2500 above the sea level (Al-Dafear
\&Al-Baha), areas with altitude 800 to 1200 meters above the sea level (El-Aqiq \& El-Mandak) and areas with altitude less than $200 \mathrm{~m}$ above the sea level (AlMekowa \& khelow). A total of twelve villages were selected for this study representing the six sectors; AL Dafear (Al-Hamaed, Hezna), Al-Baha (Khefa and Bani-Heda), El Aqiq (Al-Jawa, AlWedhia), El Mandak (Al-Nahda, and Hadabet Bel Hossien), Al Mekowa (AlMezera), and Khelow (Al-Hareka, Aiase and Al-Hega). The province is characterized by natural tree cover and agricultural plateau. Due to its location, Al-Baha's climate is moderate in summer and cold in winter.

\section{Sand fly collection and processing:}

Sand flies were collected from April to December 1995. Three collection methods were used; 1) CDC miniature light traps (John W. Hock Co., Gainesville, FL, U.S.A.) (60 traps/month). The traps were set $1 \mathrm{~h}$. before sunset and collected after sunrise next morning, 2) Aspirator collections were made off protected human bait both inside and outside houses (48 volunteers/month) and 3) Sticky paper traps consisting of $\mathrm{A}_{4}$ size paper sheets coated with castor oil and stapled vertically on wooden stakes at a height of $20 \mathrm{~cm}$. (600 traps/month). Dead and Male flies were stored in $70 \%$ alcohol and identified by using several keys (Lewis 1982; Lewis and Büttiker 1980; Büttiker and Lewis 1983; Lane 1986). Live females were immobilized on ice, dissected in $0.9 \%$ sterile saline on glass slide by making an incision at the base of the abdomen, expelling the entire gut, adding a cover slip, and examining for leishmania infection under a compound microscope at $100 \mathrm{x}$ and 400x. Females dissected in this way remained intact and were mounted for identification. The Shannon-Weiner (H), evenness (E) and richness (S) diversity indices of the collected sand flies within different localities of AlBaha province, were estimated using BioDap software (Douglas Clay, Resource conservation, Fundy National Park, Canada) as follow;

$$
H=-\sum_{i=1}^{S} P i \ln (P t)
$$

Where $p_{i}$ is the proportion of total number of species /total

$$
\text { Evenness (E): } E=H / \ln (S)
$$


Where Richness (S) is the total number of species in the community. Similarity between different habitats was estimated using Jaccard coefficient (Sij) formula;

$$
\mathrm{S}_{\mathbf{i j}=\mathbf{a} /(\mathbf{a}+\mathbf{b}+\mathbf{c})}
$$

Where $\mathrm{a}$ is the number of

present in both replicates, $\mathrm{b}$ is the number present in replicate $\mathrm{i}$ only and $\mathrm{c}$ is the number of species present in replicate $\mathrm{j}$.

\section{RESULTS}

Sand fly species composition and natural infection:

An overall total of 6,095 sand flies were collected from 12 localities representing six sectors of Al-Baha province during April to December, 1995 (Table1).

Table 1. Species composition and relative abundance of phlebotomine sand flies in Al-Baha province, Saudi Arabia during April-December, 1995.

\begin{tabular}{ccccccc}
\hline \multirow{2}{*}{ Species } & \multicolumn{2}{c}{ Male } & \multicolumn{2}{c}{ Female } & & \\
\cline { 2 - 5 } Notal & \% \\
\hline P. bergeroti & 1872 & 56.5 & 1444 & 43.5 & 3316 & 54.4 \\
P. sergenti & 503 & 55.9 & 397 & 44.1 & 900 & 14.8 \\
P. arabicus & 470 & 58.5 & 333 & 41.5 & 803 & 13.2 \\
P. alexandri & 156 & 48.3 & 167 & 51.7 & 323 & 5.3 \\
P. papatasi & 69 & 72.6 & 26 & 27.4 & 95 & 1.5 \\
P. orientalis & 33 & 41.3 & 47 & 58.7 & 80 & 1.3 \\
S. clydei & 68 & 51.9 & 63 & 48.1 & 131 & 2.1 \\
S. antennata & 101 & 68.2 & 47 & 31.8 & 148 & 2.4 \\
S. tiberiadis & 186 & 62.2 & 113 & 37.8 & 299 & 4.9 \\
Total & 3458 & & 2637 & & 6095 & \\
\hline
\end{tabular}

Nine species of phlebotomine sand flies were identified, six of genus Phlebotomus and three of genus Sergentomyia. Phlebotomus bergeroti was the most predominant species being recorded in all localities and accounted for $54.4 \%$ of the identified flies and the remaining flies were $P$. sergenti (14.8\%), $P$. arabicus (13.2 \%), P. alexandri (5.3\%), S. tiberiadis (4.9\%), S. antennata (2.4\%), S. clydei (2.1\%), $P$. papatasi $(1.5 \%)$, and $P$. orientalis (1.3\%). The overall number of collected males (3458) was more than that of the females (2,637). Depending on microscopical examination none of the sand flies dissected (1,011 females) found naturally infected with Leishmania-like flagellates.

\section{Diversity of the sand fly communities in} Al-Baha:

Sand fly communities represented differences in the diversity among different sampling sectors within Al-Baha as indicated by Shannon-Weiner index $(\mathrm{H})$ (Table 2).

The diversity was more significant in Al-Mekowa (1.68). The relatively low evenness $(E=0.55)$ and high richness (9), at Khelowa may be due to the dominance of $P$. bergeroti. The similarity between sand fly communities as examined by Jacard's coefficient $\left(I_{\text {Jacard }}\right)$ indicated that $86 \% \quad\left(I_{\text {Jacard }}=0.86\right)$ of the sand fly communities in El-Mandak and AlMekhow were similar while only 44\% (I Jacard $=0.44$ ) of the fly communities in AlBaha and Khelow were the same.

Table 2. The Shannon-Weiner diversity index $(\mathrm{H})$, evenness (E) and richness (S) for the sand fly species at different localities representing Al-Baha province, Saudi Arabia.

\begin{tabular}{lccc}
\hline Site & H & E & Richness \\
\hline Al- Dafear & 1.33 & 0.74 & 6 \\
Al-Baha & 1.12 & 0.81 & 4 \\
El-Aqiq & 0.89 & 0.65 & 4 \\
El-Mandak & 1.52 & 0.78 & 7 \\
Khelow & 1.22 & 0.55 & 9 \\
Al- Mekowa & 1.68 & 0.94 & 6 \\
\hline
\end{tabular}

Monthly abundance of the sand flies:

Sand fly activity concentrated between May and November. Different species differed in their abundance pattern between all of the sampled sites (Fig.2). In Al-Dafear and Al-Baha, $P$. sergenti, $P$. arabicus, $P$. alexandri, and $P$. papatasi were relatively active during the midseason (July) then dropped gradually until declined during November except $P$. arabicus that exhibit another peak in October. The peak of $P$. bergeroti was observed in the late season (September). In El-Aqiq, and El-Mandak, P. alexandri, $P$. bergeroti were more active during July to October then declined until disappeared from collection at the end of the season. In Khelow and Al-Mekowa, the same seasonal dynamic pattern was recorded; $P$. sergenti was active on July whereas $P$. bergeroti, and $P$. arabicus were found active during the late season (AugustSeptember). 


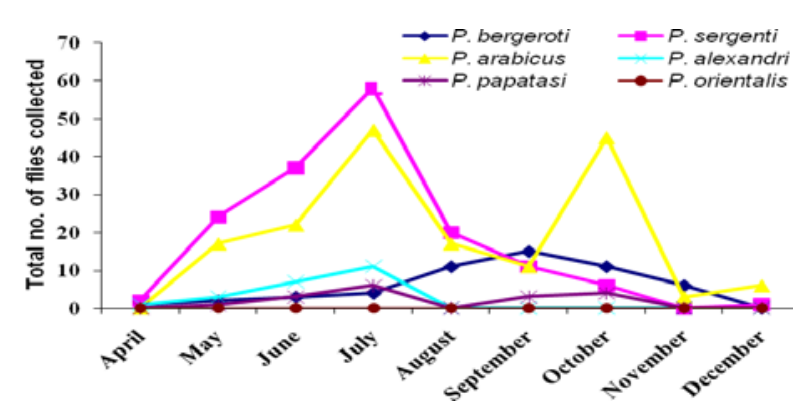

Al-Dafear

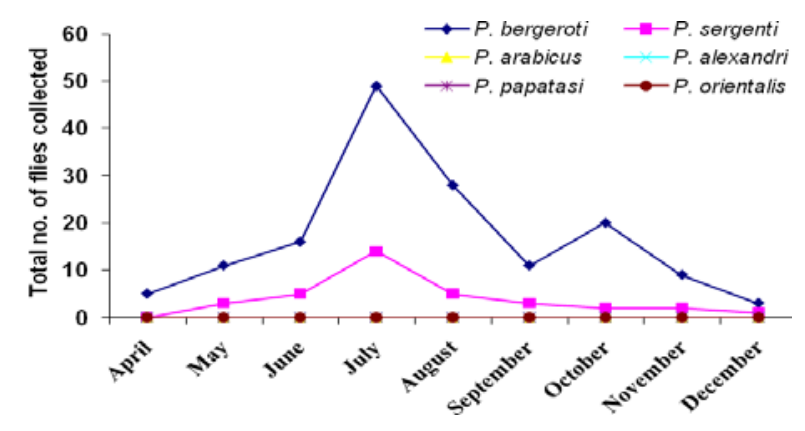

El-Aqiq

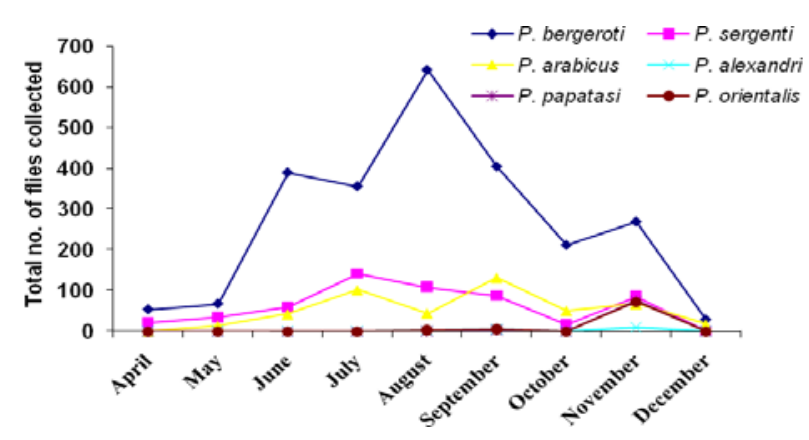

Khelow

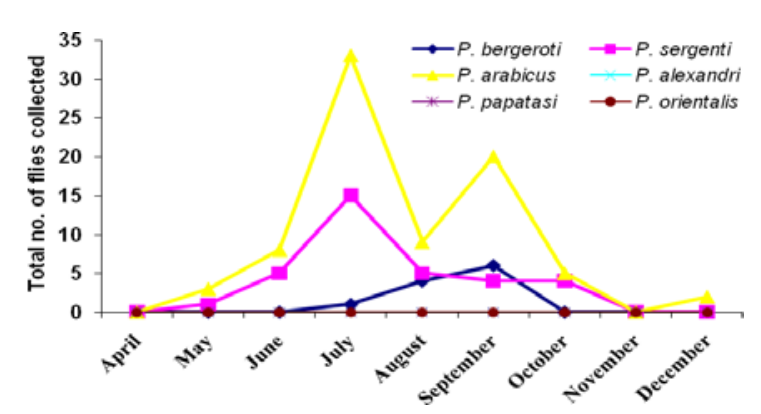

Al-Baha

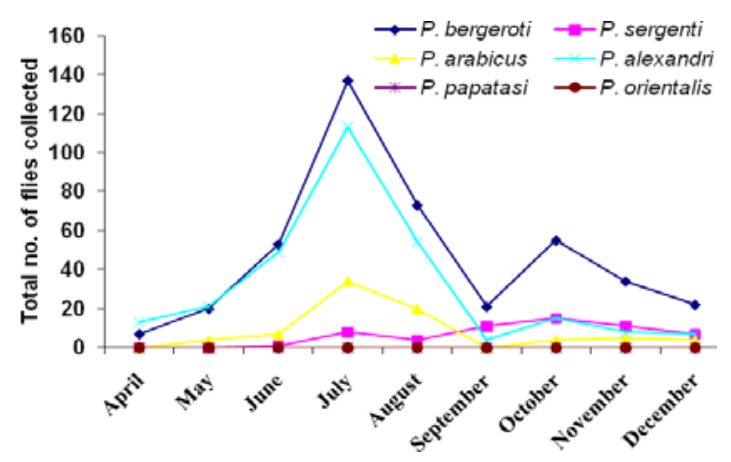

El-Mandak

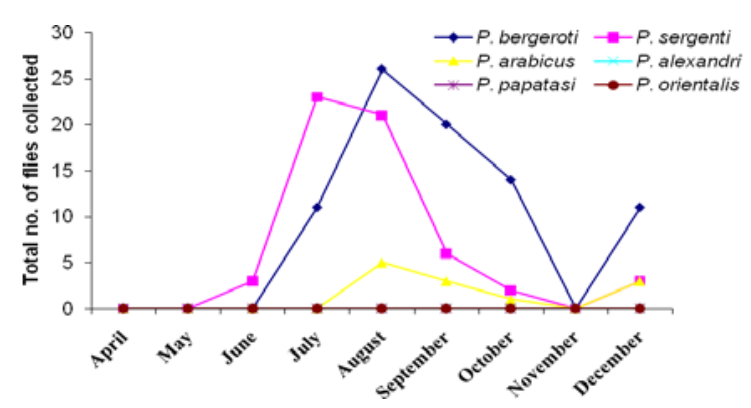

Al-Mekowa

Fig. 2: Monthly abundance of phlebotomine sand flies during April-December, 1995 in 6 localities of Al-Baha Province, Saudi Arabia.

\section{DISCUSSION}

This study reports the results of a preliminary entomological survey for the sand fly populations conducted at 6 different localities of Al-Baha province throughout April-December, 1995. The sand fly populations comprised nine species including suspected and potential vectors of leishmaniasis (Table 1 ), mainly $P$. bergeroti, $P$. sergenti, $P$. arabicus, $P$. alexandri, and $S$. tiberiadis, in descending order of abundance. The same five species were also the most abundant species reported in previous studies conducted at Riyadh (Morsy and Seghayer, 1982), Asir (Ibrahim et al., 2005), Qasim (El-Sibae et al., 1993). Most localities inside Al-Baha were wild and represent different topography. $P$. papatasi was rare and represented only $1.5 \%(95 / 6,095)$ of the total catch, this observation contradicting those of the other workers (Ibrahim et al., 2005, El-Badry et al., 2008). P. papatasi was the most abundant in peridomestic and 
domestic habitats (Coleman et al., 2007) but not in wild habitats. In the wild habitats, the number of $P$. papatasi was relatively small compared with the number of $P$. bergeroti which have the maximum abundance in Al-Baha $(3,316 / 6,095)$. The wide distribution of different sand fly species in Al-Baha may reflect a possibility for disease risk at this area associated with any change in global warming especially with the occurrence of the suspected or even the potential vectors of L. major (P. bergeroti, P. papatasi), L. tropica ( $P$. sergenti, $P$. arabicus) and $L$. infantum ( $P$. orientalis, $P$. alexandri). It was suggested that even a modest warming of the mean temperature-not more than 1 or 2 degrees $\mathrm{C}^{\circ}$ will lead to a significant spread of leishmaniasis worldwide (WHO, 1998).

Two different patterns of abundance were reported representing difference in the dynamics of the sand fly populations; 1) most species found to peak on July and then decline gradually until disappear like the population dynamic reported at AlDafear, and Al-Baha, and 2) some species reported to have a late peak during September-October like $P$. sergenti in ElMandak. These patterns of population dynamics were reported for the same species in the Middle East countries including Saudi Arabia (Ibrahim et al., 2005 and El-Badry et al., 2008), and Egypt (El-Sawaf et al., 1987, Fryauff et al., 1993, Hanafi et al., 2007). The seasonal changes reported here may be based on climatic or even topographic factors. The high temperature, low humidity during summer, different elevations, and altitudes above the sea level reported in the different sampling sites representing AlBaha may control the abundance and distribution of the sand fly species. Toward explaining our data, we carried out two successive year study (1996-1997) for sampling more sand flies from different localities representing $\mathrm{Al}-\mathrm{Baha}$ to understand the differences between the sand fly population structure, behaviour, and outlining areas of disease risk to target the disease vectors in control program.

Acknowledgments: I am grateful to staff of Primary Health Care Center, Ministry of Health, Al-Baha, Saudi Arabia especially to Mosleh El Ghobashi, Ibrahim Mesfer, and Yahia Al-Zahrani. Comments from Dr. El-Sawaf greatly improved the manuscript. Special thanks for my colleague Abdallah Samy for his technical assistance in improvement of the manuscript. The views expressed in this article are those of the author and do not necessarily reflect the official policy or position of the Egyptian or Saudian Government.

\section{REFERENCES}

Alborzi, A., Rasouli, M. and Shamsizadeh, A. (2006). Leishmania tropica infected patient with visceral leishmaniasis in southern Iran. Am. J. Trop. Med. Hyg. 74:306-307.

Al-Seghayer, S.M., Mustafa, M. B., Al faki, A. I., Al-Amri, S. A., Khoja, T. A., Farees, R., Al-Nawrani, O. A., and Abu-Geria, S. M. (1994). Epidemiological studies on cutaneous leishmaniasis in Riyadh province, central region, Kingdom of Saudi Arabia. A report of a project sponsored by King Abdel Aziz national city for sciences and technology. pp 141.

Al-Tawfiq J.A., and AbuKhamsin, A. (2004). Cutaneous leishmaniasis: a 46-year study of the epidemiology and clinical features in Saudi Arabia (1956-2002). Int J Infect Dis 8:244-250.

Al-Zahrani, M. A., Peters, W., Evans, D. A., Chin, C., Smith, V., and Lane, R. P. (1988). Phlebotomus sergenti, a vector of Leishmania tropica in Saudi Arabia. Trans. R. Soc. Trop. Med. Hyg. 82(3):416.

Al-Zahrani, M. A., Peters, W., Evans, D. A., Smith, V., and Ching Chin, I. (1989). Leishmania infecting man and wild animals in Saudi Arabia 5. Visceral leishmaniasis in man and dogs in the south west. Trans. R. Soc. Trop. Med. Hyg. 83

Büttiker W, Lewis DJ (1983). Insects of Saudi Arabia: detection of faunal biotypes of medical importance in South-Western Saudi Arabia using land sat images. Fauna Saudi Arabia 3:10 - 27.

Büttiker, W. (1979). Insects of medical importance in Saudi Arabia. Proc. Saudi Biol. Soc. 3 (Al-Hasa Conf.): 239-250.

Coleman, R. E., Burkett, D. A., Sherwood, V., Caci, J., Spradling, S., Jennings, B. T., Rowton, E., Gilmore, W., Blount, K., White, C. E., and Putnam, J. L. (2007). Impact of phlebotomine sand flies on U.S. Military operations at Tallil Air 
Base, Iraq: 2. Temporal and geographic distribution of sand flies. J. Med. Entomol. 44(1):29-41.

Desjeux, P. (2004). Leishmaniasis: current situation and new perspectives. Comp. Immunol. Microbiol. Infect. Dis. 27:305 $-318$.

El Sawaf, B. M., Shoukry, A., El Said, S., Lane, R. P., Kenawy, M. A., Beier, J. C., and Abdel Sattar, S. (1987). Sand fly species composition along an altitudinal transect in Southern Sinai, Egypt. Ann. Parasitol. Hum. Comp. 62 (58): 467473.

El-Badry A, Al-Juhani A, Ibrahim el-K, AlZubiany S. (2008). Distribution of sand flies in El-Nekheil province, in AlMadinah Al-Munawwarah region, western of Saudi Arabia. Parasitol. Res. 103(1):151-6.

El-Sibae, M. M., Eesa, N. M., and Morsy, T. A. (1993). Rodents and cutaneous leishmaniasis in Qasim, Saudi Arabia. J. Egypt. Soc. Parasitol. 23:667-673.

Fryauff, D. J., Modi, G. B., Mansour, N. S., Kreutzer, R. O., Soliman, S., and Youssef, F. G. (1993). Epidemiology of cutaneous leishmaniasis at a focus monitored by the multinational force and observers in the Northeastern Sinai Desert of Egypt. Am. J. Trop. Med. Hyg. 49(5):598-607.

Hanafi, A. H., Fryauff, D. J., Modi, G. B., Ibrahim, M. O., and Main, A. J. (2007). Bionomics of phlebotomine sand flies at a peacekeeping duty site in the north of Sinai, Egypt. Acta Tropica 101(2):106 114.

Ibrahim, A. A., and Abdoon, A. M. (2005). Distribution and population dynamics of Phlebotomus sand flies (Diptera: Psychodidae) in an endemic area of cutaneous leishmaniasis in Asir Region, Southwestern Saudi Arabia. J. Entomol. 2(1):102-108.

Killick-Kendrick R, Leaney AJ, Peters W, Rioux JA, Bray RS (1985). Zoonotic cutaneous leishmaniasis in Saudi Arabia: the incrimination of Phlebotomus papatasi as the vector in the Al-Hassa oasis. Trans. R. Soc. Trop. Med. Hyg. 79:252-255.

Lane, R. P. (1986). The sand flies of Egypt (Diptera: Phlebotominae). Bull. $\mathrm{Br}$. Mus. Nat. Hist. Entomol. 52:1-35.

Lewis DJ (1982). A taxonomic review of the genus Phlebotomus (Diptera: Psychodidae). Bull. Br. Mus. Nat. Hist. Entomol. 45:121- 209
Lewis, D. and Buttiker, W. (1980). Insects of Saudi Arabia, Diptera: Fam. Psychodidae, Subfam. Phlebotominae. Fauna of Saudi Arabia. 2, 252-285.

Lewis, D., and Buttiker, W. (1982). Insects of Saudi Arabia: the taxonomy and distribution of Saudi Arabian Phlebotomus sand flies (Diptera: Psychodidae). Fauna of Saudi Arabia. 4, 353-397.

Magill, A. J., Grogl, M., Gasser, R. A. Jr., Sun, W., and Oster, C. N. (1993). Visceral infection caused by Leishmania tropica in veterans of operation Desert Storm. N. Engl. J. Med. 328: 1383-1387.

Mebrahtu, Y. B., Lawyer, P. G., Ngumbi, P. M., Kirigi, G., Mbugua, J., Gachihi, G., Wasunna, K., Pamba, H., Sherwood, J. A., and Koech, D. K. (1992). A new rural focus of cutaneous leishmaniasis caused by Leishmania tropica in Kenya. Trans. R. Soc. Trop. Med. Hyg. 86:381387.

Morsy, T. A., and al Seghayer, S. M. (1992). A brief note on phlebotomine sand flies in Riyadh, Saudi Arabia. J. Egypt. Soc. Parasitol. 22(2):437-40.

Peters, W., and Al-Zahrani, M.A. (1987). The leishmaniases: a public health problem in Saudi Arabia. Saudi Med. J. 8:333343.

Peters,W., Elbihari, S., Liu, C., Le Blancq, S.M., Evans, D.A., Killick-Kendrick, R., Smith, V., and Baldwin, C.I. (1985). Leishmania infecting man and wild animals in Saudi Arabia. 1. General survey. Trans. R. Soc. Trop. Med. Hyg. 79:831-839.

Sang, D. K., Njeru, W. K., and Ashford, R. W. (1992). A possible animal reservoir for Leishmania tropica s.l . in Kenya. Ann. Trop. Med. Parasitol. 86: 311-312.

Shehata, M.G., Samy, A.M., Doha, S.A., Fahmy, A.R., Kaldas, R.M., Furman, B.D., and Villinski J.T. (2009). First report of Leishmania tropica from a classical focus of L. major in NorthSinai, Egypt. Am. J. Trop. Med. Hyg. 81 (2): 213-218.

Svobodova, M., Votypka, J., Peckova, J., Dvorak, V., Nasereddin, A., Baneth, G., Sztern, J., Kravchenko, V., Orr, A., Meir, D., Schnur, L. F., Volf, P., and Warburg, A. (2006). Distinct transmission cycles of Leishmania tropica in 2 adjacent foci, Northern Israel. Emerg. Infect. Dis. 12(12):18608.

The World Health Report, 1998. Geneva: WHO, 1998. 


\section{ARABIC SUMMARY}

ذباب الرمل الفلوباتاميني في مناطق مختلفة من أمارة الباحة بالمملكة العربية السعودية

\section{سعيد عبدالله ضحا}

مركز الأبحاث و الدر اسات و التدريب لناقلات الأمر اض، جامعة عين شمس، العباسيه، القاهرة، مصر.

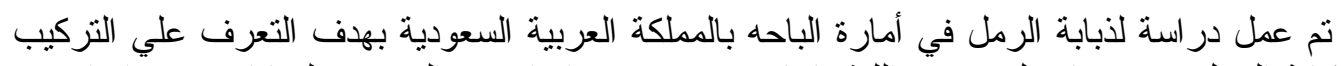

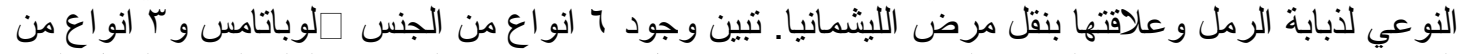

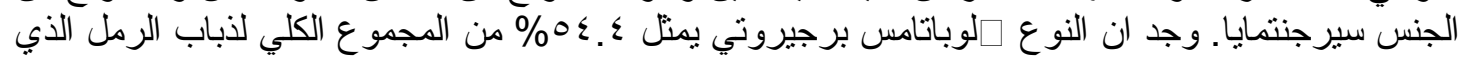

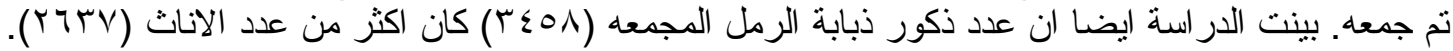

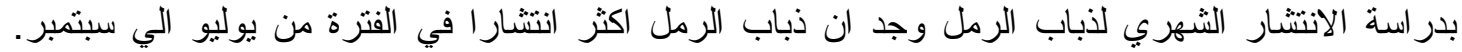

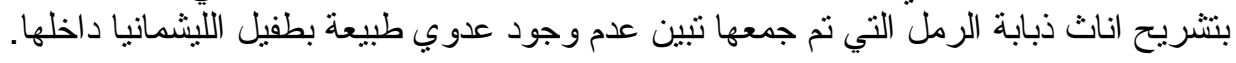

